\title{
Pirfenidone activates cannabinoid receptor 2 in a mouse model of bleomycin-induced pulmonary fibrosis
}

\author{
JINHONG LIU ${ }^{1}$ and GUILING SHI ${ }^{2}$ \\ ${ }^{1}$ Department of Pharmacy, Tianjin Baodi Hospital, Baodi Clinical College of Tianjin Medical University, \\ Tianjin 301800; ${ }^{2}$ Department of Pharmacy, Tianjin People's Hospital, Tianjin 300121, P.R. China
}

Received March 20, 2018; Accepted August 21, 2019

DOI: $10.3892 / \mathrm{etm} .2019 .8045$

\begin{abstract}
Inflammation serves an important role in the pathogenesis of idiopathic pulmonary fibrosis (IPF). Cannabinoid receptor $2(\mathrm{CB} 2 \mathrm{R})$ is a receptor predominantly expressed in the immune system. CB2R agonists can be used to treat a wide range of inflammation-related diseases. Pirfenidone has been demonstrated to be effective for IPF treatment. The aim of present study was to investigate whether CB2R activation mediates the antifibrotic effect of pirfenidone. For that purpose, mice were intravenously injected with bleomycin (BLM; $5 \mathrm{mg} / \mathrm{kg} / \mathrm{day})$. pirfenidone (300 mg/kg/day) was then orally administered for 15 days. Lung pathological alterations in the mice were evaluated by Masson's trichrome staining. The mRNA and protein levels of CB2R in lung tissues were measured by reverse transcription-quantitative PCR and western blotting. The levels of inflammatory factors were determined by ELISA. The effect of pirfenidone on WI38 cell viability was evaluated by MTT assay. The results demonstrated that $\mathrm{CB} 2 \mathrm{R}$ protein and $\mathrm{mRNA}$ levels increased with increasing fibrosis in mice with BLM-induced IPF. Pirfenidone administration significantly ameliorated IPF and reduced the serum levels of inflammatory factors induced by BLM. Pirfenidone also inhibited fibroblast cell proliferation and decreased the levels of inflammatory factors in vitro, which could be reversed by the CB2R antagonist SR144528, suggesting that $\mathrm{CB} 2 \mathrm{R}$ was activated by pirfenidone. In conclusion, pirfenidone attenuated and activated $\mathrm{CB} 2 \mathrm{R}$ in BLM-treated mice. In addition, pirfenidone inhibited fibroblast cell proliferation in vitro. These effects could be reversed by the CB2R antagonist SR144528. Thus, activation of CB2R may be considered a mechanism of the antifibrotic effects of pirfenidone.
\end{abstract}

Correspondence to: Mr. Jinhong Liu, Department of Pharmacy, Tianjin Baodi Hospital, Baodi Clinical College of Tianjin Medical University, 8 Chuan Street, Baodi, Tianjin 301800, P.R. China E-mail: liujh0018@163.com

Key words: pulmonary fibrosis, pirfenidone, cannabinoid receptor 2, inflammation, bleomycin

\section{Introduction}

Idiopathic pulmonary fibrosis (IPF) is a chronic, progressive and severe lung disease characterized by aggressive progression and poor prognosis (1). Although its exact etiology is poorly understood, IPF is characterized by abnormal extracellular matrix (ECM) deposition, including excessive collagen deposition (2,3). Lung transplantation used to be the only effective treatment known for IPF prior to 2014, when a novel antifibrotic agent, pirfenidone, was approved by the Food and Drug Administration in the United States and by the European Medicines Agency for the treatment of IPF (4). A previous study demonstrated that pirfenidone treatment was effective in extending survival time and stabilizing pulmonary function in patients with IPF (5). Pirfenidone was able to suppress the infiltration of inflammatory cells into the bronchoalveolar lavage fluid (BALF) and reduce the transcription of transforming growth factor- $\beta$ (TGF- $\beta$ ) in a hamster model of IPF $(6,7)$. In addition, pirfenidone could protect mice from endotoxic shock by reducing the levels of tumor necrosis factor- $\alpha$ (TNF- $\alpha$ ) and increasing the levels of interleukin (IL)-10 (8). However, the potential mechanism responsible for the antifibrotic properties of pirfenidone is not fully understood.

Cannabinoid receptor 2 (CB2R) is a G protein-coupled receptor that is predominantly expressed in the spleen and cells of the immune system (9), although CB2R is also expressed in non-immune cells such as pulmonary endothelial cells (10). Unlike CB1R, CB2R agonists do not exhibit psychoactive effects, which suggests that targeting CB2R may be a potential treatment of a wide range of inflammation-related diseases (11). A previous study demonstrated that CB2R was activated in cirrhotic livers, and $\mathrm{CB} 2 \mathrm{R}^{-/}$mice developed increased fibrosis, indicating that CB2R may have an antifibrogenic role (12). Activation of CB2R by JWH133 alleviates bleomycin (BLM)-induced IPF in mice (13). In addition, a recent study has demonstrated that treatment with pirfenidone for 2 years could decrease fibrosis and cytokine levels, as well as enhance $\mathrm{CB} 2 \mathrm{R}$ gene expression, in patients with chronic hepatitis C (14). However, whether CB2R is involved in the antifibrotic effect of pirfenidone remains to be fully elucidated.

The present study aimed to investigate whether CB2R was involved in the antifibrotic effect of pirfenidone in BLM-induced IPF in mice. The results indicated that pirfenidone could attenuate IPF and activate CB2R in BLM-treated 
mice, as well as inhibit fibroblast cell proliferation in vitro, which could be reversed by the CB2R antagonist SR144528. These data indicated that activation of CB2R may be considered a mechanism of the antifibrotic effects of pirfenidone.

\section{Materials and methods}

Animals. Male C57BL/6 mice (weight, 18-20 g; age, 8 weeks; $\mathrm{n}=10$ in each group) were provided by the Model Animal Research Center of Nanjing University. Animals were kept under a 12-h light/dark cycle at room temperature $\left(22 \pm 2^{\circ} \mathrm{C}\right)$ and $55 \pm 5 \%$ humidity, with food and water provided ad libitum. All the procedures used in the present study were performed according to the National Institutes of Health Guide for the Care and Use of Laboratory Animals (15). The animal protocols were approved by the Baodi Clinical College of Tianjin Medical University Animal Care Committee.

Animal model of IPF. A well-established animal model of IPF was used in the present study, as previously described (3). Animals were randomly assigned into four groups: i) Control group, which was intravenously injected with $50 \mu 10.9 \%$ saline; ii) BLM group, which was intravenously injected with $5 \mathrm{mg} / \mathrm{kg} /$ day BLM (Nippon Kayaku Co., Ltd.) in $50 \mu \mathrm{l}$ saline for 28 consecutive days; iii) BLM + pirfenidone group, which was orally administered $300 \mathrm{mg} / \mathrm{kg} /$ day pirfenidone (Shionogi \& Co., Ltd.) in $0.5 \%$ carboxymethylcellulose (CMC; $40 \mathrm{mg} / \mathrm{ml} ; 7.5 \mathrm{ml} / \mathrm{kg} /$ day, Cayman Chemical Co.); and iv) $\mathrm{BLM}+\mathrm{CMC}$ group, which was orally administered with equal amounts of CMC for 14 days after the 28-day treatment with BLM. The dosage was determined according to a previous study (16). On days 0, 5, 10 and 15 since the first pirfenidone administration, mice were sacrificed by exsanguination under deep anesthesia (sodium pentobarbital intraperitoneal injection, $50 \mathrm{mg} / \mathrm{kg}$ ). Lung tissues were then removed from each mouse via a midline incision and the left lung lobes were fixed in $4 \%$ paraformaldehyde (Wako Pure Chemical Industries, Ltd.) for $48 \mathrm{~h}$ at room temperature, embedded in paraffin and processed to obtain 5- $\mu \mathrm{m}$ sections for Masson's trichrome staining, and the right lung lobes were frozen in liquid nitrogen at $-80^{\circ} \mathrm{C}$ for reverse transcription-quantitative PCR (RT-qPCR) and western blotting. The time points used in the current study were selected according to previous studies that investigated fibrocyte accumulation $\sim 14$ days after BLM treatment (17-19).

Cell culture. The human embryonic lung fibroblast cell line WI38 was purchased from Shanghai Institutes for Biological Sciences. WI38 cells were maintained in Dulbecco's modified Eagle medium (DMEM) containing 10\% fetal bovine serum (both Gibco; Thermo Fisher Scientific, Inc.), $100 \mathrm{U} / \mathrm{ml}$ penicillin and $100 \mathrm{U} / \mathrm{ml}$ streptomycin at $37^{\circ} \mathrm{C}$ in a humidified atmosphere with $5 \% \mathrm{CO}_{2}$. At $50 \%$ confluency, the culture medium was replaced with serum-free DMEM for $24 \mathrm{~h}$ prior to treatment with BALF extracted from BLM-treated mice. BALF was prepared as previously described (20). Briefly, after 7 days of treatment with BLM, mice were sacrificed, and a plastic cannula was inserted into the trachea. A cold sterile saline solution was gently injected to perform bronchoalveolar lavage (BAL). The BALF was centrifuged at
$700 \mathrm{x} \mathrm{g}$ at $4^{\circ} \mathrm{C}$ for $5 \mathrm{~min}$, and the supernatant was stored at $-80^{\circ} \mathrm{C}$ until further use.

WI38 cells were incubated with an equal volume of DMEM and BALF containing $200 \mu \mathrm{g} / \mathrm{ml}$ pirfenidone, $20 \mu \mathrm{M}$ JWH-015 (a CB2R-selective agonist) or $1 \mu \mathrm{M} \mathrm{SR} 144528$ (a $\mathrm{CB} 2 \mathrm{R}$ antagonist) for $48 \mathrm{~h}$ at $37^{\circ} \mathrm{C}$. JWH-015 and SR144528 were obtained from Cayman Chemical Co. The concentration of drugs was determined according to a previous study (21).

Histological analysis. Lung tissues were fixed in 4\% paraformaldehyde and then embedded in paraffin as described above. Paraffin sections (5- $\mu \mathrm{m}$ thick) were prepared and stained with Masson's trichrome stain at room temperature for $10 \mathrm{~min}$. Stained sections were observed using a light microscope equipped with a DFC490 digital camera (magnification, x400; Leica Microsystems $\mathrm{GmbH}$ ).

$R T-q P C R$. Total RNA was isolated from mouse lung tissue and WI38 cells with TRIzol ${ }^{\circledR}$ reagent (Invitrogen; Thermo Fisher Scientific, Inc) according to the manufacturer's instructions. Complementary DNA synthesis was performed using the PrimeScript ${ }^{\mathrm{TM}}$ RT Master Mix reagent kit (Takara Biotechnology Co., Ltd.) at the following conditions: Initial incubation at $37^{\circ} \mathrm{C}$ for $15 \mathrm{~min}$, followed by incubation at $85^{\circ} \mathrm{C}$ for $5 \mathrm{sec}$, and then analyzed using SYBR ${ }^{\circledR}$ Premix Ex Taq ${ }^{\mathrm{TM}}$ kit (Takara Biotechnology Co., Ltd.) in a 7500 Fast Real-Time PCR System (Applied Biosystems; Thermo Fisher Scientific, Inc.). qPCR was performed using the following protocol: Initial denaturation at $94^{\circ} \mathrm{C}$ for $1 \mathrm{~min} ; 45$ cycles of denaturation at $94^{\circ} \mathrm{C}$ for $30 \mathrm{sec}$, annealing at $58^{\circ} \mathrm{C}$ for $30 \mathrm{sec}$ and extension at $72^{\circ} \mathrm{C}$ for $30 \mathrm{sec}$. The primers used were as follows: Mouse CB2R forward, 5'-ATGGCCGTGCTCTATATTATCCT-3' and reverse, 5'-ATGGTCACACTGCCGATCTTC-3'; human embryonic lung fibroblast cell line WI38 CB2R forward, 5'-GGGTGACAGAGATAGCCAATGG-3' and reverse, 5'-TGAACAGGTATGAGGGCTTCC-3'; collagen I forward, 5'-AACTTTGCTTCCCAGATGTCCT-3' and reverse, 5'-TCG GTGTCCCTTCATTCCAG-3'; and GAPDH forward, 5'-GGA TTTGGTCGTATTGGG-3' and reverse, 5'-GGAAGATGG TGATGGGATT-3'. GAPDH was used as the endogenous control. The relative expression level of the target gene was calculated using the $2^{-\Delta \Delta \mathrm{Cq}}$ method (22).

Western blotting. Lung tissues and cells were lysed in SDS sample buffer (62.5 mM Tris- $\mathrm{HCl}$ pH 6.8, 2.5\% SDS, $0.002 \%$ Bromophenol Blue, $5 \% \beta$-mercaptoethanol and $10 \%$ glycerol) and subjected to western blot analysis as previously described (16). Protein concentrations were determined using the BCA method. Protein samples were separated by SDS-PAGE $(10 \% \mathrm{gel})$ and then transferred to polyvinylidene fluoride membranes (EMD Millipore), which were then blocked with $5 \%$ dry milk for $1 \mathrm{~h}$ at room temperature. Membranes were subsequently incubated with primary antibodies against CB2R (40 kDa; cat. no. ab3561; 1:1,000; Abcam) and GAPDH (37 kDa; cat. no. ab8245; 1:1,000; Abcam) overnight at $4^{\circ} \mathrm{C}$. Horseradish peroxidase-conjugated secondary goat anti-mouse immunoglobulin $\mathrm{G}$ antibody (1:2,000; cat. no. 1015-05, Southern Biotech) was added for $1 \mathrm{~h}$ at room temperature. Each sample was measured in triplicate. Enhanced chemiluminescence was used to detect the proteins. 

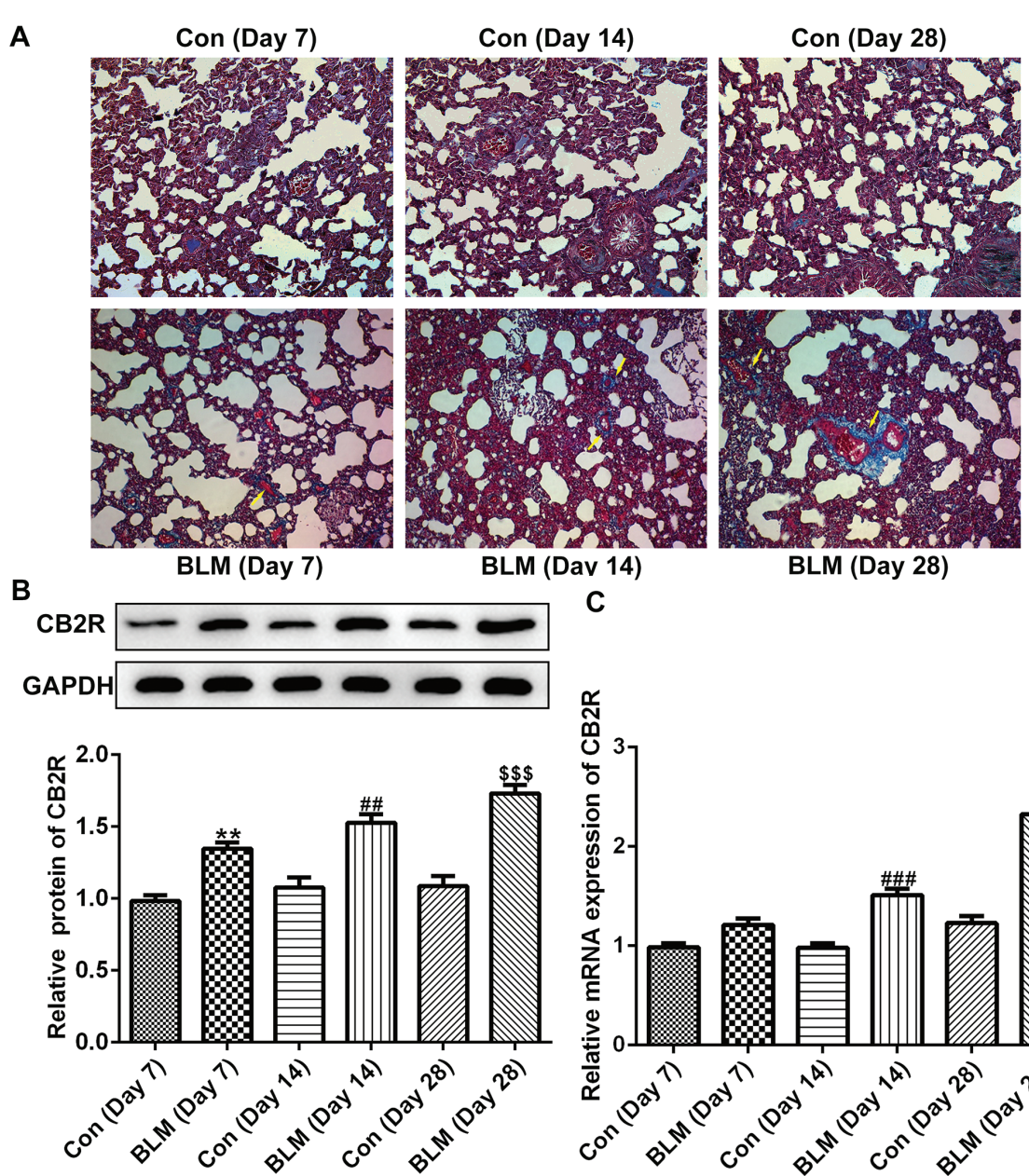

C

BLM (Day 28)

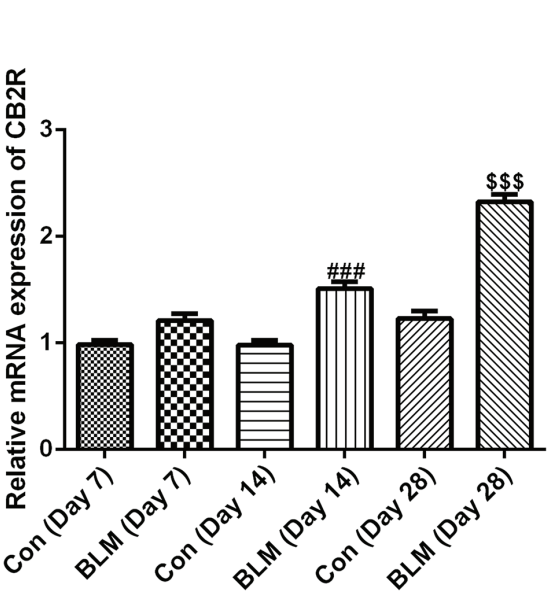

Figure 1. CB2R expression is increased in BLM-induced mice pulmonary fibrosis. BLM was used to induce pulmonary fibrosis in C57BL/6 mice. (A) Masson staining revealed a degree of pulmonary fibrosis in mice at 7, 14 and 28 days after BLM injection. ( $\mathrm{n}=10$ mice). Magnification, $\mathrm{x} 400$. (B) The protein levels of CB2R at 14 and 28 days after BLM injection were detected by western blotting. (C) The mRNA levels of CB2R at 14 and 28 days after BLM injected were detected by reverse transcription-quantitative PCR. Data are presented as the mean \pm SEM. ${ }^{* *} \mathrm{P}<0.01$ vs. the Con (Day 7 ) group; ${ }^{\# \#} \mathrm{P}<0.01,{ }^{\# \# \#} \mathrm{P}<0.001$ vs. Con (Day 14) group; ${ }^{\$ \$ S} \mathrm{P}<0.001$ vs. Con (Day 28) group. Con, control; BLM, bleomycin; CB2R, CB2 receptor.

Images were captured using ChemiDoc ${ }^{\mathrm{TM}}$ XRS (Bio-Rad Laboratories, Inc.). The density of bands was determined using the Image $\mathbf{J}$ software (version 1.46; National Institutes of Health).

ELISA. The levels of inflammatory cytokines IL-6 (cat. no. 550950; BD Biosciences), IL-1 $\beta$ (IL-1 $\beta$, cat. no. MLB00C; R\&D systems, Inc.) and TNF- $\alpha$ (TNF- $\alpha$; cat. no. 560478; BD Biosciences) in the supernatant of cultured lung fibroblasts and in mouse serum were analyzed with corresponding ELISA kits, according to the manufacturer's protocols.

Cell proliferation assay. MTT assay was used to assess the proliferation of fibroblasts. WI38 cells were plated onto 96-well plates at a density of $8 \times 10^{3}$ cells per well and cultured for $24 \mathrm{~h}$ at $37^{\circ} \mathrm{C}$. Vybrant ${ }^{\circledR}$ MTT Cell Proliferation Assay kit (Thermo Fisher Scientific, Inc.) was used 24, 48 and $72 \mathrm{~h}$ after drug administration (BALF with pirfenidone $(0,100$, $200,400,600$, and $800 \mu \mathrm{g} / \mathrm{ml})$ according to the manufacturer's protocol. A total of $20 \mu \mathrm{l}$ MTT $(5 \mathrm{mg} / \mathrm{ml})$ was added to each well for a further 4-h incubation at $37^{\circ} \mathrm{C}$, and $150 \mu \mathrm{l}$ dimethyl sulfoxide (Sigma Aldrich; Merck KGaA) was added to each well. Subsequently, the absorbance (A) was measured at $570 \mathrm{~nm}$ on a microplate reader (Thermo Fisher Scientific, Inc.). The cell viability was calculated using the following equation: Cell viability $=\mathrm{A}_{\text {treatment }} / \mathrm{A}_{\text {control }} \times 100 \%$. Additionally, prior to the MTT assay, cell morphology in each group was observed using a light microscope (magnification, x200; Leica Microsystems GmbH).

Statistical analysis. SPSS version 17.0 software (SPSS, Inc.) was used to conduct the statistical analysis. All data are generated from experiments that was repeated at least 3 times, and expressed as the mean \pm standard error of the mean. Statistical significance among groups was evaluated using one-way analysis of variance followed by the Tukey-Kramer post hoc test. $\mathrm{P}<0.05$ was considered to indicate a statistically significant difference.

\section{Results}

$C B 2 R$ expression is increased in a mouse model of $B L M$-induced IPF. As shown in Fig. 1A, compared with the control group, the pulmonary fibrotic area in the experimental 

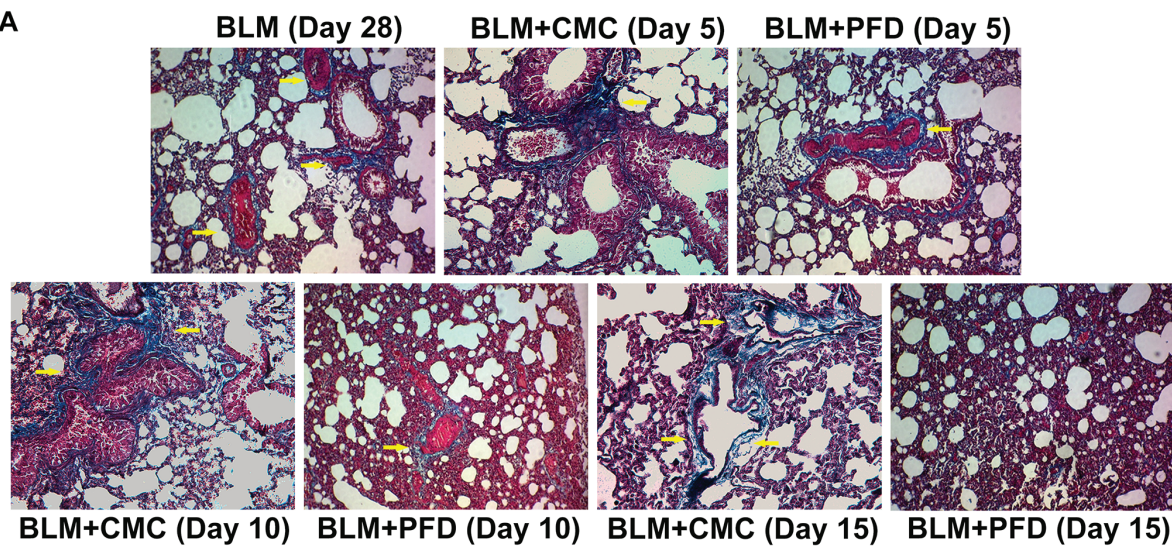

B
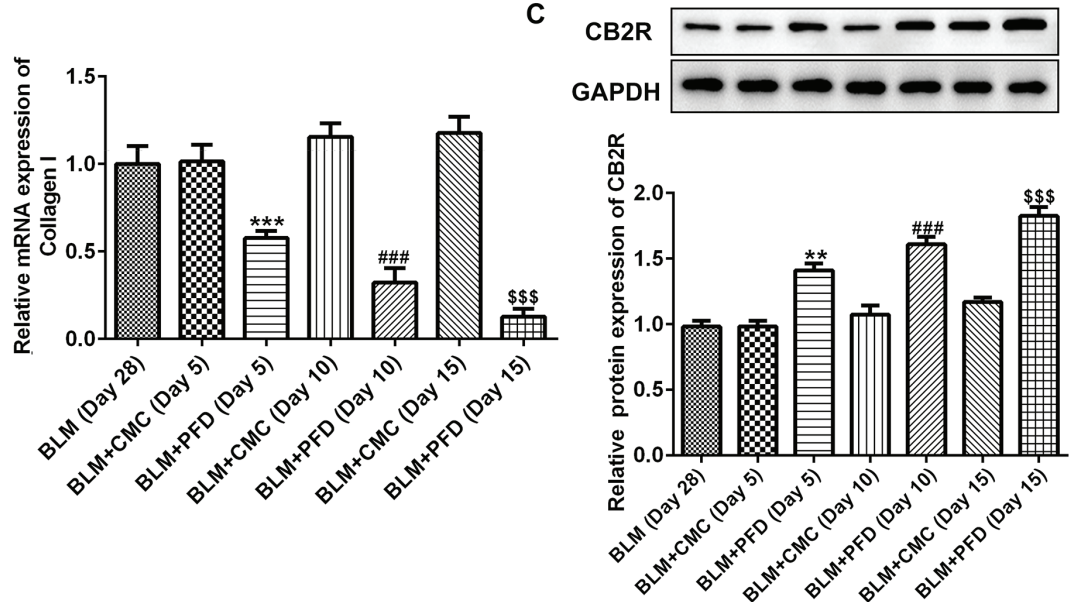

Figure 2. PFD upregulated CB2R expression in mice with BLM-induced pulmonary fibrosis. (A) The degree of fibrosis in the lungs of mice in the BLM, BLM + CMC and BLM + PFD (day 5, 10 or 15) groups were detected by Masson staining. Magnification, $x 400$. (B) The mRNA level of type I collagen in the lungs of mice detected by reverse transcription-quantitative PCR. (C) The protein levels of CB2R in the lungs of mice detected by western blotting. Data are presented as the mean \pm SEM. ${ }^{* *} \mathrm{P}<0.01$ vs. the BLM + CMC (Day 5) group; ${ }^{* * * *} \mathrm{P}<0.001$ vs. the BLM + CMC (Day 5) group; ${ }^{\# \# "} \mathrm{P}<0.001$ vs. BLM + CMC (Day 10) group; ${ }^{\$ \$ \$} \mathrm{P}<0.001$ vs. BLM + CMC (Day 15) group. BLM, bleomycin; PFD, pirfenidone; CB2R, CB2 receptor.

mice was markedly increased on days 7, 14 and 28 after BLM injection. In addition, the protein and mRNA levels of CB2R were increased at days 14 and 28 after BLM injection compared with the respective control groups (Fig. 1B and C).

Pirfenidone activates $C B 2 R$ in mice with BLM-induced IPF. As shown in Fig. 2A, histological examination revealed that the fibrotic areas in the BLM + PFD mice were markedly reduced compared with the BLM + CMC group 10 or 15 days after the administration of pirfenidone. Furthermore, type I collagen content was quantified in the lungs to evaluate the antifibrotic effects of pirfenidone. As shown in Fig. 2B, the mRNA level of type I collagen in the lungs of pirfenidone-treated mice was significantly reduced compared with that observed in BLM + CMC-treated mice at days 5, 10 and 15. In addition, administration of pirfenidone significantly increased the protein level of CB2R compared with that exhibited by the BLM + CMC group at days 5, 10 and 15 (Fig. 2C). These results indicated that CB2R expression was upregulated by pirfenidone treatment. Furthermore, the levels of the inflammatory factors IL-1 $\beta$, IL- 6 and TNF- $\alpha$ in mouse serum were detected by ELISA. The results revealed that administration of pirfenidone significantly reduced the serum concentration of the inflammatory cytokines at days 5,
10 and 15 compared with the respective BLM + CMC groups (Fig. 3). These results suggested that the activation of CB2R may be considered a mechanism of the antifibrotic effects of pirfenidone.

Activation of CB2R mediates the protective effect of pirfenidone on BALF-treated WI38 cells. To further confirm whether the activation of $\mathrm{CB} 2 \mathrm{R}$ mediated the protective effect of pirfenidone on BLM-induced IPF, human embryonic lung fibroblast WI38 cells were incubated with BALF from BLM-treated mice. Increasing concentrations of pirfenidone $(0,100,200,400,600$, and $800 \mu \mathrm{g} / \mathrm{ml})$ were added to the culture medium for 24,48 or $72 \mathrm{~h}$. The MTT assay was used to assess the effects of pirfenidone on the growth kinetics of BALF-treated WI38 cells. Pirfenidone reduced BALF-treated WI38 cell viability in a time- and concentration-dependent manner (Fig. 4A). In addition, to establish the role of pirfenidone in CB2R expression in BLM-induced mice pulmonary fibrosis, pirfenidone $(200 \mu \mathrm{g} / \mathrm{ml})$ was added to BALF-treated WI38 cells. As shown in Fig. 4B and C, administration of $200 \mu \mathrm{g} / \mathrm{ml}$ pirfenidone to BALF-treated WI38 cells for $48 \mathrm{~h}$ significantly increased the protein and mRNA levels of CB2R compared with the untreated control group. This effect was reversed by the CB2R antagonist SR144528. In addition, 

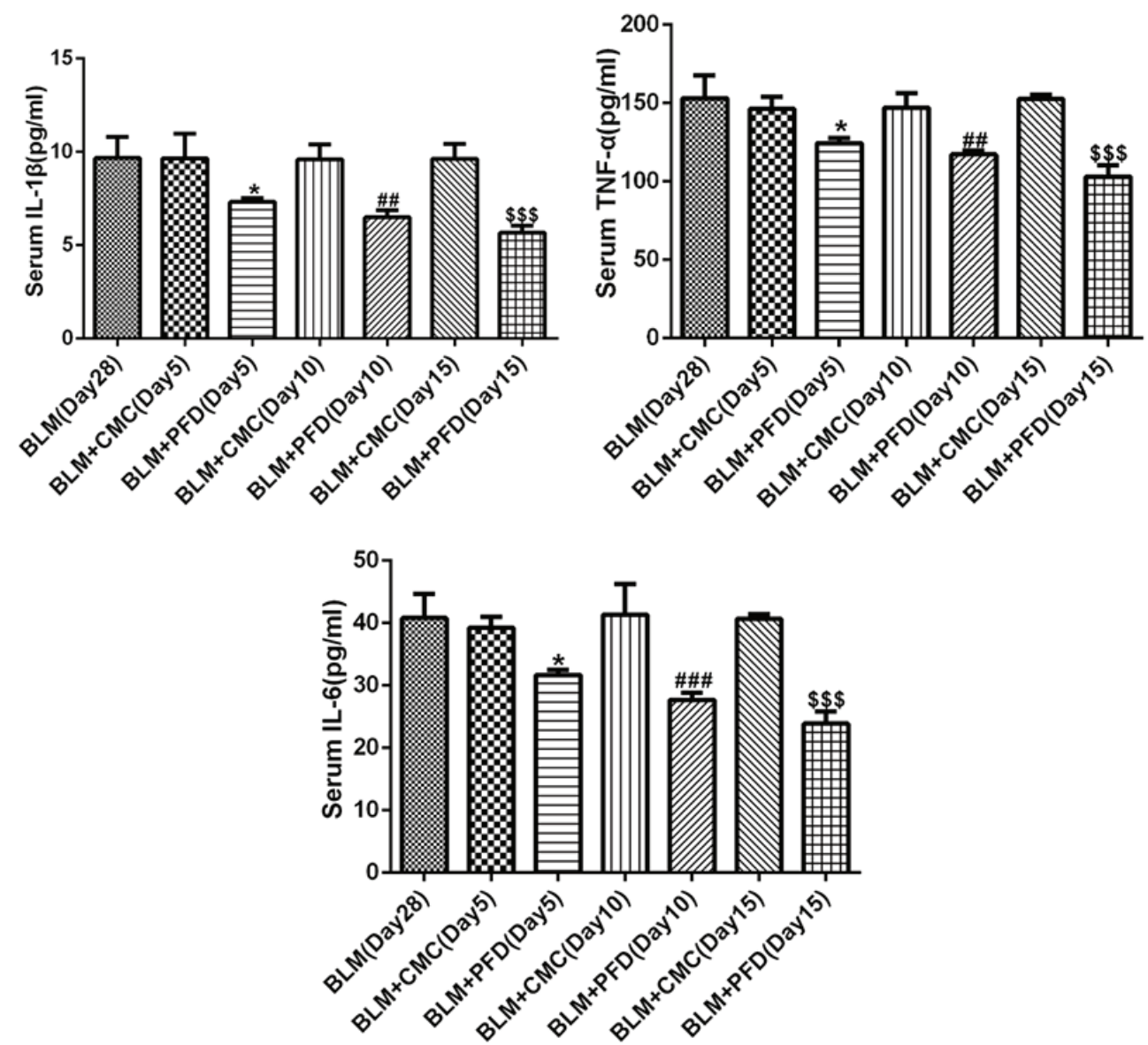

Figure 3. Effect of PFD on BLM-induced IL-1 $\beta$, IL-6 and TNF- $\alpha$ expressions in serum of mice. The levels of IL-1 $\beta$, IL- 6 and TNF- $\alpha$ in serum of mice were detected by ELISA. Data are presented as the mean \pm SEM. ${ }^{*} \mathrm{P}<0.05$ vs. the $\mathrm{BLM}+\mathrm{CMC}$ (Day 5) group; ${ }^{\# \#} \mathrm{P}<0.01,{ }^{\# \# \#} \mathrm{P}<0.001$ vs. BLM $+\mathrm{CMC}$ (Day 10 ) group; ${ }^{\$ \$} \mathrm{P}<0.001$ vs. BLM + CMC (Day 15) group. BLM, bleomycin; PFD, pirfenidone; CB2R, CB2 receptor; IL, interleukin; TNF- $\alpha$, tumor necrosis factor- $\alpha$.

compared with the untreated control group, pirfenidone significantly decreased the viability of WI38 cells, which was reversed by the CB2R antagonist SR144528 (Fig. 4D and E). Furthermore, WI38 cells treated with pirfenidone secreted less TNF- $\alpha$, IL- $1 \beta$ and IL-6 than untreated control cells. The anti-inflammatory effect of pirfenidone could also be reversed by the CB2R antagonist SR144528 (Fig. 4F-H). The effects of pirfenidone on BALF-treated WI38 cells were similar to those caused by the $\mathrm{CB} 2 \mathrm{R}$-selective agonist JWH-015 (Fig. 4B-H).

\section{Discussion}

The clinical efficacy and safety of pirfenidone in patients with IPF have been demonstrated in several multinational, randomized, double-blind, placebo-controlled, phase 3 clinical trials, and the cumulative data were summarized in a recent study by Lancaster et al (23). The present results demonstrated that pirfenidone attenuated BLM-induced IPF in mice, which is consistent with the results of previous studies $(24,25)$. In addition, pirfenidone could activate $\mathrm{CB} 2 \mathrm{R}$ in mice with BLM-induced IPF.

IPF is defined as a specific form of chronic progressive lung disease attributed to multiple factors associated with inflammation, oxidative stress and accumulation of fibroblasts/myofibroblasts, leading to abnormal deposition of extracellular collagen (26), where a single pharmacological intervention often fails to incur a multifaceted protective role (27). The results of the current study revealed that pirfenidone could attenuate, but not completely reverse, BLM-induced pulmonary fibrosis, which was consistent with a previous study (24).

Organ fibrosis is the result of excessive and irreversible deposition of ECM, particularly collagen. Cytokines are centrally engaged in maintaining the homeostatic balance of the ECM, and the recruitment and release of inflammatory cytokines can stimulate the proliferation of fibroblasts and the synthesis of ECM (28). A previous study has reported that the levels of IL-1 $\beta$ and IL- 6 were upregulated in BALF in BLM-induced lung fibrosis in vivo (29). In addition, BLM administration stimulated the mRNA expression of profibrotic cytokines IL-13 and IL-4, and the alternatively activated macrophages (M2) markers including, arginase 1, resistin-like a, $\mathrm{C}-\mathrm{C}$ motif chemokine $(\mathrm{Ccl}) 17$ and $\mathrm{Ccl} 24$ in cells collected from BALF in a BLM-induced lung fibrosis mouse model (30). The expression of IL-6, IL-8, TNF- $\alpha$ and TGF- $\beta$ was upregulated in BLM-treated rat lung tissues (31). These results indicated that the expression of inflammatory cytokines and fibrogenic mediators was significantly elevated in BALF in BLM-induced lung fibrosis. Previous studies have 


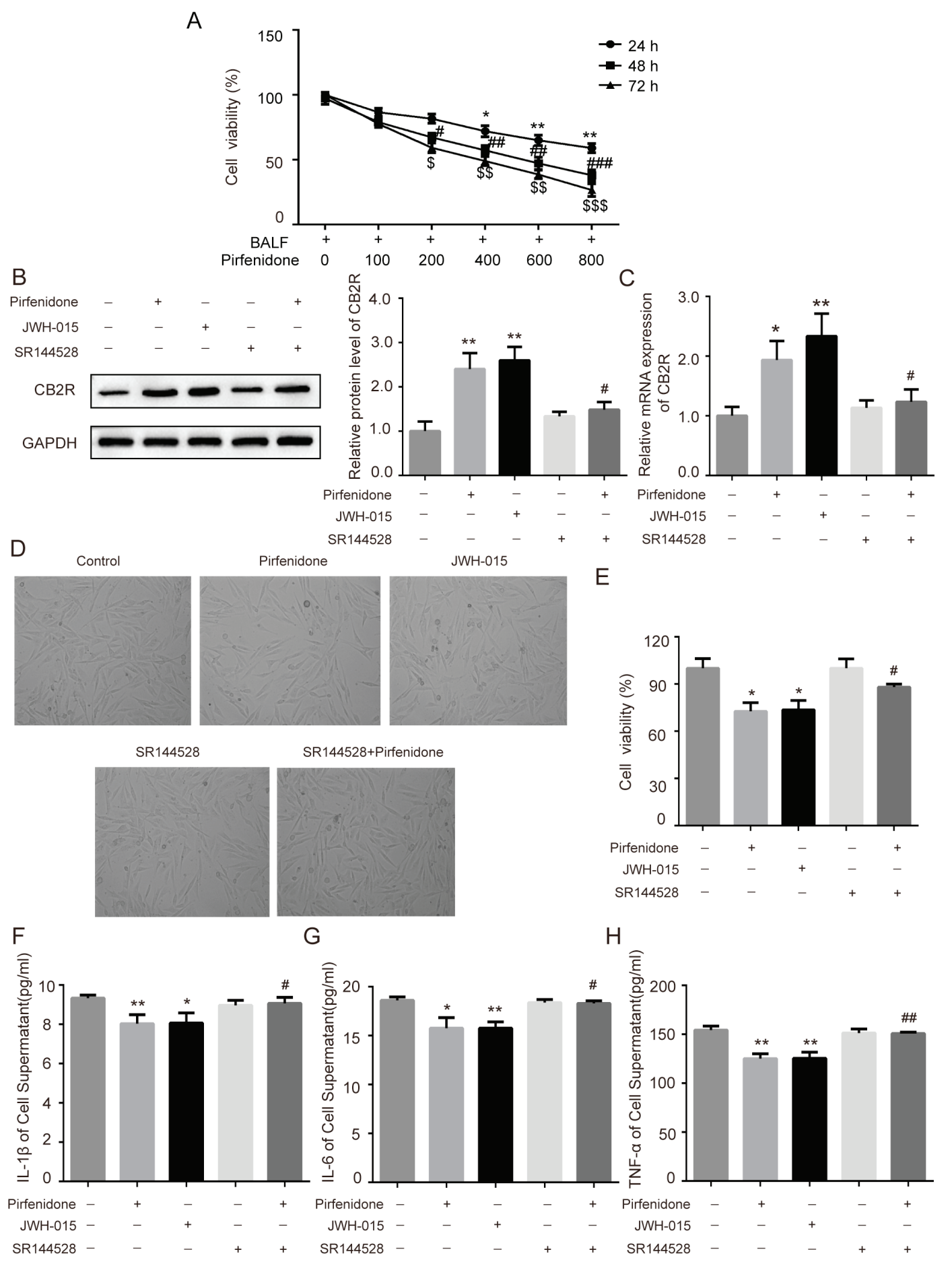

Figure 4. Activation of CB2R mediates the protective effect of PFD on BALF-treated WI38 cells. WI38 cells were incubated with BALF from bleomycin-treated mice and treated with $200 \mu \mathrm{g} / \mathrm{ml}$ pirfenidone, $20 \mu \mathrm{M} \mathrm{JWH}-015,1 \mu \mathrm{M} \mathrm{SR} 144528$, and $200 \mu \mathrm{g} / \mathrm{ml}$ pirfenidone $+1 \mu \mathrm{M}$ SR144528. (A) The MTT assay was performed to determine the viability of WI38 cells treated with various concentrations of pirfenidone $(0,100,200,400,600$, and $800 \mu \mathrm{g} / \mathrm{ml})$ for 24,48 or $72 \mathrm{~h}$. Data are presented as the mean \pm SEM. ${ }^{*} \mathrm{P}<0.05,{ }^{* *} \mathrm{P}<0.01$ vs. cell group only treated with BALF for $24 \mathrm{~h} ;{ }^{\#} \mathrm{P}<0.05,{ }^{\# \prime} \mathrm{P}<0.01,{ }^{\# \# \#} \mathrm{P}<0.001$ vs. cell group only treated with BALF for $48 \mathrm{~h} ;{ }^{\$} \mathrm{P}<0.05,{ }^{\$ \$} \mathrm{P}<0.01,{ }^{\$ \$ \$} \mathrm{P}<0.001 \mathrm{vs}$. cell group only treated with BALF for $72 \mathrm{~h}$. The protein and mRNA levels of CB2R were detected by (B) western blotting and (C) RT-qPCR. (D) WI38 cell proliferation was observed under a light microscope (magnification, x40) and detected by MTT assay. (E) Quantitative analysis of cell proliferation rate. The levels of (F) IL-1 $\beta$, (G) IL-6 and (H) TNF- $\alpha$ in cell culture supernatant were detected by ELISA. Data are presented as the mean \pm SEM. ${ }^{*} \mathrm{P}<0.05,{ }^{* *} \mathrm{P}<0.01$ vs. untreated control group; ${ }^{"} \mathrm{P}<0.05,{ }^{\# \#} \mathrm{P}<0.01$ vs. $\mathrm{PFD}$ only group. $\mathrm{PFD}$, pirfenidone; $\mathrm{CB} 2 \mathrm{R}$, CB2 receptors; BALF, bronchoalveolar lavage fluid.

reported that IL-6 has pro-fibrotic effects both in vitro and in vivo, and that the inhibition of IL- 6 could attenuate PF in animal models through the STAT3 signaling pathway $(32,33)$. IL-1 $\beta$ has an indirect pro-fibrotic effect in silica-induced lung fibrosis in C57BL/6 mice or in fibroblasts (34-36). TNF- $\alpha$ is a pro-inflammatory cytokine, which can cause fibrosing alveolitis in mice (37). A previous study has reported that TGF- $\beta 1$ could induce proliferation of WI38 fibroblasts (38). Therefore, in the current study, WI38 cells were incubated with BALF from BLM-treated mice to induce fibrosis in vitro. The results 
of the present study demonstrated that the administration of pirfenidone significantly decreased the levels of pro-inflammatory cytokines and mRNA levels of type I collagen in mice with BLM-induced IPF. These results indicated that the antifibrotic effect of pirfenidone may be partly mediated by anti-inflammatory mechanisms.

CB2R is mainly expressed in the immune system (39). A previous study has reported that $\mathrm{CB} 2 \mathrm{R}$ expression was detected in cultured hepatic myofibroblasts and in activated hepatic stellate cells which triggered a potent antifibrogenic effect. To the best of our knowledge, Julien et al (12) was the first to demonstrate that CB2R is highly upregulated in the cirrhotic liver, predominantly in hepatic fibrogenic cells. Michler et al (40) reported that activation of CB2R could reduce inflammation in acute experimental pancreatitis through a p38-dependent signaling pathway. In a previous study, the expression levels of $\mathrm{CB} 2 \mathrm{R}$ were increased in rats with acute and chronic cystitis (41). Furthermore, it was reported that endocannabinoids could reduce ulcerative colitis-associated inflammation through binding to CB2R (42). CB2R was previously reported to be activated in liver fibrosis (12). TGF- $\beta 1$ could induce mouse lung fibroblasts and increase the levels of CB2R, while CB2R agonist JWH133 decreased TGF- $\beta 1$-induced pulmonary fibrosis (13). In addition, celastrol alleviates renal fibrosis by upregulating cannabinoid receptor 2 expression (43). These results indicated that CB2R may be upregulated in pulmonary fibrosis and activation of CB2R may reduce pulmonary fibrosis. In addition, a previous study has demonstrated that treatment with pirfenidone for 2 years could decrease fibrosis and cytokine levels such as IL-6, as well as enhance CB2R gene expression, in patients with chronic hepatitis (14). Therefore, it may be hypothesized that pirfenidone plays a protective role against pulmonary fibrosis by upregulating CB2R expression. The present results revealed that $\mathrm{CB} 2 \mathrm{R}$ expression was upregulated in BLM-induced IPF of mouse model, whilst pirfenidone significantly increased the expression of CB2R in mice with BLM-induced IPF and in BALF-treated WI38 cells, which could be reversed by the CB2R antagonist SR144528, suggesting that SR144528 could block CB2R endogenous activity and inhibit its upregulated expression caused by pirfenidone. CB2R agonist JWH-015 could activate $\mathrm{CB} 2 \mathrm{R}$, along with an upregulated CB2R expression, while pirfenidone also increased CB2R expression. CB2R antagonist SR144528 effectively inhibited pirfenidone-induced upregulated CB2R expression, suggesting that pirfenidone may increase $\mathrm{CB} 2 \mathrm{R}$ expression by activating $\mathrm{CB} 2 \mathrm{R}$ endogenous activity. In addition, the anti-inflammatory effects of pirfenidone in BALF-treated WI38 cells could also be reversed by the CB2R antagonist SR144528. The present results indicated that the activation of $\mathrm{CB} 2 \mathrm{R}$ may be involved in the antifibrotic effects of pirfenidone.

In conclusion, pirfenidone significantly attenuated BLM-induced lung fibrosis in mice, which may be mediated by $\mathrm{CB} 2 \mathrm{R}$ activation. However, the present report is a preliminary study, since it did not elucidate whether the activation of CB2R is the direct effect of pirfenidone or the result of a secondary effect. In addition, the present study did not determine the location of CB2R in lung tissues. Thus, further studies are required to elucidate the role and underlying mechanism of CB2R.

\section{Acknowledgements}

Not applicable.

\section{Funding}

No funding was received.

\section{Availability of data and materials}

The datasets used and/or analyzed during the present study are available from the corresponding author on reasonable request.

\section{Authors' contributions}

JL wrote the manuscript, and analyzed and interpreted the data. GS searched the literature, collected the data, designed the study and revised the manuscript.

\section{Ethics approval and consent to participate}

The animal protocols were approved by the Baodi Clinical College of Tianjin Medical University Animal Care Committee.

\section{Patient consent for publication}

Not applicable.

\section{Competing interests}

The authors declare that they have no competing interests.

\section{References}

1. Raghu G, Collard HR, Egan JJ, Martinez FJ, Behr J, Brown KK, Colby TV, Cordier JF, Flaherty KR, Lasky JA, et al: An official ATS/ERS/JRS/ALAT statement: Idiopathic pulmonary fibrosis: Evidence-based guidelines for diagnosis and management. Am J Respir Crit Care Med 183: 788-824, 2011.

2. Pardo A and Selman M: Idiopathic pulmonary fibrosis: New insights in its pathogenesis. Int J Biochem Cell Biol 34: 1534-1538, 2002.

3. Lynch JR III, Saggar R, Weigt SS, Zisman DA and White ES: Usual interstitial pneumonia. Semin Respir Crit Care Med 27: 634-651, 2006.

4. Antoniou KM, Wuyts W, Wijsenbeek M and Wells AU: Medical therapy in idiopathic pulmonary fibrosis. Semin Respir Crit Care Med 37: 368-377, 2016.

5. Taguchi Y, Ebina M, Hashimoto S, Ogura T, Azuma A, Taniguchi H, Kondoh Y, Suga M, Takahashi H, Nakata K, et al: Efficacy of pirfenidone and disease severity of idiopathic pulmonary fibrosis: Extended analysis of phase III trial in Japan. Respir Investig 53: 279-287, 2015.

6. Iyer SN, Gurujeyalakshmi G and Giri SN: Effects of pirfenidone on transforming growth factor-beta gene expression at the transcriptional level in bleomycin hamster model of lung fibrosis. J Pharmacol Exp Ther 291: 367-373, 1999.

7. Iyer SN, Gurujeyalakshmi G and Giri SN: Effects of pirfenidone on procollagen gene expression at the transcriptional level in bleomycin hamster model of lung fibrosis. J Pharmacol Exp Ther 289: 211-218, 1999.

8. Oku H, Shimizu T, Kawabata T, Nagira M, Hikita I, Ueyama A, Matsushima S, Torii M and Arimura A: Antifibrotic action of pirfenidone and prednisolone: Different effects on pulmonary cytokines and growth factors in bleomycin-induced murine pulmonary fibrosis. Eur J Pharmacol 590: 400-408, 2008. 
9. Pertwee RG: Pharmacology of cannabinoid receptor ligands Curr Med Chem 6: 635-664, 1999.

10. Zoratti C, Kipmen-Korgun D, Osibow K, Malli R and Graier WF: Anandamide initiates $\mathrm{Ca}(2+)$ signaling via $\mathrm{CB} 2$ receptor linked to phospholipase $\mathrm{C}$ in calf pulmonary endothelial cells. $\mathrm{Br} \mathrm{J}$ Pharmacol 140: 1351-1362, 2003.

11. Piomelli D, Giuffrida A, Calignano A and Rodríguez de Fonseca F: The endocannabinoid system as a target for therapeutic drugs. Trends Pharmacol Sci 21: 218-224, 2000.

12. Julien B, Grenard P, Teixeira-Clerc F, Van Nhieu JT, Li L, Karsak M, Zimmer A, Mallat A and Lotersztajn S: Antifibrogenic role of the cannabinoid receptor CB2 in the liver. Gastroenterology 128: 742-755, 2005.

13. Fu Q, Zheng Y, Dong X, Wang L and Jiang CG: Activation of cannabinoid receptor type 2 by JWH133 alleviates bleomycin-induced pulmonary fibrosis in mice. Oncotarget 8: 103486-103498, 2017.

14. Flores-Contreras L,Sandoval-Rodriguez AS, Mena-EnriquezMG, Lucano-Landeros S, Arellano-Olivera I, Alvarez-Álvarez A, Sanchez-Parada MG and Armendáriz-Borunda J: Treatment with pirfenidone for two years decreases fibrosis, cytokine levels and enhances CB2 gene expression in patients with chronic hepatitis C. BMC Gastroenterol 14: 131, 2014.

15. Committee for the Update of the Guide for the Care and Use of Laboratory Animals: Guide for the care and use of laboratory animals. (8th edition). National Academies Press, Washington, 2011.

16. Liu Y, Lu F, Kang L, Wang Z and Wang Y: Pirfenidone attenuates bleomycin-induced pulmonary fibrosis in mice by regulating Nrf2/Bach1 equilibrium. BMC Pulm Med 17: 63, 2017.

17. Phillips RJ, Burdick MD, Hong K, Lutz MA, Murray LA, Xue YY, Belperio JA, Keane MP and Strieter RM: Circulating fibrocytes traffic to the lungs in response to CXCL12 and mediate fibrosis. J Clin Invest 114: 438-446, 2004.

18. Song JS, Kang CM, Kang HH, Yoon HK, Kim YK, Kim KH, Moon HS and Park SH: Inhibitory effect of CXC chemokine receptor 4 antagonist AMD3100 on bleomycin induced murine pulmonary fibrosis. Exp Mol Med 42: 465-472, 2010.

19. Ishida $\mathrm{Y}$, Kimura A, Kondo T, Hayashi T, Ueno M, Takakura N, Matsushima K and Mukaida N: Essential roles of the $\mathrm{CC}$ chemokine ligand 3-CC chemokine receptor 5 axis in bleomycin-induced pulmonary fibrosis through regulation of macrophage and fibrocyte infiltration. Am J Pathol 170: 843-854, 2007

20. Song P, Zheng JX, Xu J, Liu JZ, Wu LY and Liu C: $\beta$-catenin induces A549 alveolar epithelial cell mesenchymal transition during pulmonary fibrosis. Mol Med Rep 11: 2703-2710, 2015.

21. Montecucco F, Burger F, Mach F and Steffens S: CB2 cannabinoid receptor agonist JWH-015 modulates human monocyte migration through defined intracellular signaling pathways. Am J Physiol Heart Circ Physiol 294: H1145-H1155, 2008.

22. Livak KJ and Schmittgen TD: Analysis of relative gene expression data using real-time quantitative PCR and the 2(-Delta Delta C(T)) method. Methods 25: 402-408, 2001.

23. Lancaster L, Albera C, Bradford WZ, Costabel U, du Bois RM, Fagan EA, Fishman RS, Glaspole I, Glassberg MK, King TE Jr, et al: Safety of pirfenidone in patients with idiopathic pulmonary fibrosis: Integrated analysis of cumulative data from 5 clinical trials. BMJ Open Respir Res 3: e000105, 2016.

24. Inomata M, Kamio K, Azuma A, Matsuda K, Kokuho N, Miura Y, Hayashi H, Nei T, Fujita K, Saito Y and Gemma A: Pirfenidone inhibits fibrocyte accumulation in the lungs in bleomycin-induced murine pulmonary fibrosis. Respir Res 15: $16,2014$.

25. Schaefer CJ, Ruhrmund DW, Pan L, Seiwert SD and Kossen K Antifibrotic activities of pirfenidone in animal models. Eur Respir Rev 20: 85-97, 2011.

26. Sgalla G, Biffi A and Richeldi L: Idopathic pulmonary fibrosis: Diagnosis, epidemiology and natural history. Respirology 21 : 427-437, 2016.
27. Foucquier $\mathbf{J}$ and Guedj $\mathrm{M}$ : Analysis of drug combinations: Current methodological landscape. Pharmacol Res Perspect 3: e00149, 2015.

28. Lebda MA, Sadek KM, Abouzed TK, Tohamy HG and El-Sayed YS: Melatonin mitigates Thioacetamide-induced hepatic fibrosis via antioxidant activity and modulation of Proinflammatory cytokines and Fibrogenic genes. Life Sci 192: 136-143, 2018.

29. Aumiller V, Balsara N, Wilhelm J, Gunther A and Konigshoff M: WNT/ $\beta$-catenin signaling induces IL- $1 \beta$ expression by alveolar epithelial cells in pulmonary fibrosis. Am J Respir Cell Mol Biol 49: 96-104, 2013

30. Zhao J, Okamoto Y, Asano Y, Ishimaru K, Aki S, Yoshioka K, Takuwa N, Wada T, Inagaki Y, Takahashi C, et al: Sphingosine-1phosphate receptor-2 facilitates pulmonary fibrosis through potentiating IL-13 pathway in macrophages. PLoS One 13: e197604, 2018

31. Dong X, Li X, Li M, Chen M, Fan Q and Wei W: Inhibitory effects of thalidomide on bleomycin-induced pulmonary fibrosis in rats via regulation of thioredoxin reductase and inflammations. Am J Transl Res 9: 4390-4401, 2017.

32. Le TT, Karmouty-Quintana H, Melicoff E, Le TT, Weng T, Chen NY, Pedroza M, Zhou Y, Davies J, Philip K, et al: Blockade of IL-6 trans signaling attenuates pulmonary fibrosis. J Immunol 193: 3755-3768, 2014

33. O'Donoghue RJ, Knight DA, Richards CD, Prêle CM, Lau HL, Jarnicki AG, Jones J, Bozinovski S, Vlahos R, Thiem S, et al: Genetic partitioning of interleukin-6 signalling in mice dissociates Stat3 from Smad3-mediated lung fibrosis. EMBO Mol Med 4: 939-951, 2012.

34. Zhang L, Yan JW, Wang YJ, Wan YN, Wang BX, Tao JH, Chen B, Li BZ, Yang GJ and Wang J: Association of interleukin 1 family with systemic sclerosis. Inflammation 37: 1213-1220, 2014.

35. Mia MM, Boersema M and Bank RA: Interleukin-1 $\beta$ attenuates myofibroblast formation and extracellular matrix production in dermal and lung fibroblasts exposed to transforming growth factor- $\beta 1$. PLoS One 9: e91559, 2014.

36. Guo J, Gu N, Chen J, Shi T, Zhou Y, Rong Y, Zhou T, Yang W, Cui X and Chen W: Neutralization of interleukin-1 beta attenuates silica-induced lung inflammation and fibrosis in C57BL/6 mice. Arch Toxicol 87: 1963-1973, 2013.

37. Miyazaki Y, Araki K, Vesin C, Garcia I, Kapanci Y, Whitsett JA, Piguet PF and Vassalli P: Expression of a tumor necrosis factor-alpha transgene in murine lung causes lymphocytic and fibrosing alveolitis. A mouse model of progressive pulmonary fibrosis. J Clin Invest 96: 250-259, 1995.

38. Huang X, Wang W, Yuan H, Sun J, Li L, Wu X, Luo J and $\mathrm{Gu}$ Y: Sunitinib, a small-molecule kinase inhibitor, attenuates bleomycin-induced pulmonary fibrosis in mice. Tohoku J Exp Med 239: 251-261, 2016

39. Cabral GA, Raborn ES, Griffin L,Dennis J and Marciano-Cabral F $\mathrm{CB} 2$ receptors in the brain: Role in central immune function. Br J Pharmacol 153: 240-251, 2008.

40. Michler T, Storr M, Kramer J, Ochs S, Malo A, Reu S, Göke B and Schäfer C: Activation of cannabinoid receptor 2 reduces inflammation in acute experimental pancreatitis via intra-acinar activation of $\mathrm{p} 38$ and MK2-dependent mechanisms. Am J Physiol Gastrointest Liver Physiol 304: 181-192, 2013.

41. Merriam FV, Wang ZY, Guerios SD and Bjorling DE: Cannabinoid receptor 2 is increased in acutely and chronically inflamed bladder of rats. Neurosci Lett 445: 130-134, 2008.

42. Marquéz L, Suárez J, Iglesias M, Bermudez-Silva FJ, Rodríguez de Fonseca F and Andreu M: Ulcerative colitis induces changes on the expression of the endocannabinoid system in the human colonic tissue. PLoS One 4: e6893, 2009.

43. Tang M, Cao X, Zhang K, Li Y, Zheng QY, Li GQ, He QH, $\mathrm{Li}$ SJ, Xu GL and Zhang KQ: Celastrol alleviates renal fibrosis by upregulating cannabinoid receptor 2 expression. Cell Death Dis 9: 601, 2018 .

This work is licensed under a Creative Commons Attribution-NonCommercial-NoDerivatives 4.0 International (CC BY-NC-ND 4.0) License. 